\title{
Småting om Jens Madsen \\ Hanved sogn som dansk kulturprovins
}

Af Poul Kürstein.

Arene 1850 til 1864 er sprogreskripternes tid i Sønderjylland. Ved disse regeringsbestræbelser søgte man at fremme dansken i skole og kirke på dens gamle enemærker i Mellemslesvig, d. v. s. den nordlige del af det nuværende Sydslesvig, hvor dansk endnu var menigmands mål, helt eller delvis. Dette stræb blev kastet over ende af de ulykkelige hændelser i 1864, men det satte sig dog sine spor hos menigmand.

Af endnu længere blivende værdi var den videnskabelige udforskning af landet, dets sprog og historie. Den satte frugter $\mathrm{i}$ bøger som Sejdelins Diplomatarium Flensborgense, C. F. Allens Det danske Sprogs Historie i Hertugdømmet Slesvig, Traps Hertugdømmet Slesvig samt det blandede historiske tidsskrift Slesvigske Provindsialefterretninger. Dettes bedste og navnkundigste bidrag var vel H. F. Feilbergs Fra Heden, en skildring af folkelivet i Vis, Kær og Ugle herreder, som siden kom som selvstændig bog 1863 med 2. udgave i 1920 .

\section{Jens Madsens vise.}

Mindre kendt $\mathrm{i}$ almenheden, men højt værdsat af fagfolk er »Folkeminder fra Hanved Sogn ved Flensborg, samlede og udgivne af Jens Madsen «. Han samlede minderne, mens han var lærer $\mathrm{i}$ Ellund fra 1858 til 1864, da han blev smidt ud af preusserne, og bogen udkom i Kobenhavn i 1870. Men inden da havde han sin meget væsentlige andel $\mathrm{i}$ pastor Feilbergs skildring, hvad denne fuldt ud anerkendte $i$ sit forord: "Hermed sender jeg en tak til de mange, som har udfyldt og berigtiget mine optegnelser; iblandt 


\title{
Folkemintor
}

fra

\section{Sandeb Sogu veb flengorg,}

\author{
famlebe og ubginne
}

af

Itns gmadrex.

Entles bet en Sang at germanifere Rorbfesuig, faa ex Danfthebens Dam: ning brubt, faa vil zyfferne uben शRje ubbrebe fig lige til Sfagen.

(\$. Colderlunb, Hfortallinger og Skilbringrt" E. 159.)

Xijogenfjaun.

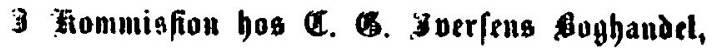

(E. 5. xillge).

Marrebrog̉ Bogtryfteri, (Ar. Eriffen).

1870.

Titelblad $i$ naturlig storrelse. 
dem må jeg nævne lærer J. Madsen i Ellund, som med sjxlden uegennyttighed har stillet sine værdifulde samlinger til min uindskrænkede rådighed, og hvem det fornemmelig skyldes, at jeg har kunnet meddele så mange viser både fra nutid og fortid«. En udførlig skildring af Jens Madsens værk er givet af August F. Schmidt i Sønderjysk Månedsskrift, 1943, bd. 19.

Jens Madsen havde et så overvældende stof til sin bog, at han ofte har kortet sine viser af, således nr. 27, hvor han omhyggeligt gør rede for, at versene 2, 3, 5, 7 og 8 mangler. I et eksemplar, som tilhører Dansk Centralbibliotek i Flensborg, ligger der et par sedler med de manglende vers undtagen vers 7 , og der står, at de er $»$ tilføjet $i$ året 1910 af købmand Nis Jensen Branderup. Opholdt sig i Harreslev fra sit 3de til 16 år «. Også Harreslev ligger i Hanved sogn, og Nis Jensen Branderup har også tilføjelser til en anden vise, men vi holder os nu til nr. 27 og bringer Jens Madsens vers og Nis Jensen Branderups tilføjelser; de sidste trykkes med kursiv, så at man kan skelne dem fra hinanden.'

Tilføjelserne er interessante, fordi de vidner om Jens Madsens pålidelighed som optegner af viser, og fordi de fortæller om bogens brug i Sønderjylland og on Nis Jensens egen adhu til sagen.

1. Imens jeg Frihed haver, og Tiden er mig lang, jeg nu til Pennen tager og skrive vil en Sang; thi mit Hjerte er beklemt, og jeg er saa ilde stemt alt for Dig, min søde Pige, som har mig saa rent forglemt.

2. Jeg maatte fra Dig vandre Da jeg $i$ Heren trén Men strax $D u$ tog en anden En mere megtig en Skjøndt Du tidt bar lovet mig Aldrig at forlade mig Forend Døden os adskiller Her paa denne Jorderig.
3. I Aarbus jeg nu ligger Der er min Garnison Og Kongen jeg maa tjene Alt som en rask Dragon Men ibvor jeg gaar og staar Alt mit Hjerte for dig slaar Og jeg fole maa stor Smerte Alt for Dig min yndig (Maar?)

4. Thi Du har mig foragtet, fordi jeg ej var rig,

Og Du har eftertragtet en mere magtelig; thi Du plukker Blomster smaa, mens jeg maa i Sorgen gaa, men maaske de snart bortsvinder, Rigdom den kan snart forgaa. 
5. Ja Rigdom kan bortsvinde Som Dug for Solens Skin Da maa Dit Øie rinde For en ustadig Ven Thi naar Rigdom den forgaar

$\mathrm{Da}$ er Kjarlighed ei stor Da kan Du i Sorgen leve Her paa denne Verdens Jord

6. Du har mit Hjerte krænket og fort i Sorgen stor og bundet udi Lanker i mine unge Aar. Gid jeg kunde glemme Dig, o, da var jeg lykkelig, men Din kjxre Røst og Stemme den vil stedse staa for mig.
8. O maatte jeg nu spørge Om Dig som var min Ven Du har en god Forsarger Og lever med ham ben Udi Glede og $i$ Flor Her paa denne Verdens Jord At Du stedse og maa bave Hvad Du onsker her paa Jord

9. Til Slutning vil jeg bede for Dig, som var min Ven, at Gud Dig vil vejlede, ihvor $\mathrm{Du}$ rejser hen. Skjøndt Du var utro mod mig, vil jeg dog tilgive Dig og Dig Held og Lykke onske, indtil Døden kalder Dig.

7. Dette vers mangler håde hos Jens Madsen og Nis Jensen, Branderupl.

De folkelige viser handler ofte om øm elskov, men tiest dog om den ulykkelige og svigtede kxrlighed. Tit er det pigen, det går hårdest ud over, men også manden rammes af svig. Det sker gerne, mens karlen som $\mathrm{i}$ denne vise er $\mathrm{i}$ kongens tjeneste, $\mathrm{i}$ Århus ved de jyske dragoner. Selve soldatertjenesten klager sangeren aldrig over, men kun over dens følger: at den skiller ham fra den elskede pige, nu og da for evigt som her. Som rimeligt er, har salmebogen i ikke ringe grad været litterært forbillede. Dens ord og rytme synger igennem visen jæunsides med ældre folkeviser.

Her må det huskes, at Kær herred først fik fast tysk kirkesprog ved reskripterne af 1768, 1777 og 1778, og at adskillige sogne havde danske katekismer før denne tid.' Brugen af Pontoppidans salmebog i disse sogne er mulig, ja sandsynlig. Hertil kommer også en mulig privat udbredelse af ikke-autoriserede salmesamlinger som Cassuben, Rachløws Tåreperse og herrnhutiske udgivelser. Og ikke mindst de åndelige viser, som falbødes i étblads-tryk på markederne, har haft betydning. Vi véd det med sikkerhed for Tønders vedkommende og har derfor ret til at antage det for markederne i Lxk, Nibøl, Hanved og Bredsted. Sidste sted solgte folk fra Store Vi deres korn, og folk fra de tre herreder kom både til Tonder og Flensborg. Over- 
hovedet kan viserne i rigsmål være kommet til de tre herreder som skillingstryk. ${ }^{4}$

Verset $\mathrm{i}$ den gengivne vise er meget kunstfærdigt. Der skiftes rytme midt $i$ verset, og linje 5, 6 og 8 rimer med mandlig udgang, mens linje 7 står udfordrende ene med kvindelig udgang og uden rim til nogen af siderne. Selv om man ikke kan påstå, at verset er et fuldendt kunstværk, er dets digter ingen stymper, da han $i$ høj grad lever op til sit eget xrgerrige mål, som er sat med den krævende versform. Visse brist $\mathrm{i}$ rimene kan forklares, hvis man antager, at digterens modersmål ikke er rigsdansk, men jysk, sønderjysk.

Jens Madsen og H. F. Feilberg har optegnet adskillige sagn, gåder, remser og viser $\mathrm{i}$ egnens stedmål. Det er den almindelige folkedigtning fra hele det danske sprogs område. Men der findes hos begge talrige viser og sange, der er optegnet på rigsmålet. Så sent som i 1930'erne kunne Broder Ketelsen optegne adskillige af dem, og endnu i 1960'erne har Karl Clausen optaget sange på rigsmålet på bånd. I Hanved og de omliggende sogne havde der før 1850 været tysk skole- og kirkesprog. ${ }^{5}$

Af dette kan vi slutte, at der ikke blot har været en dansk digtning på folkemålet i Vis, Ugle og Kær herreder, men også, at der har været tradition for litterær brug af det danske kultursprog, og den må være ældre end sprogreskripternes danske skole og kirke 1850-64. Det viser allerede mængden af viser, og endnu flere vidnesbyrd om påvirkning fra dansk rigsmålskultur lod sig let føre.

Denne litterære rigsmålstradition har $i$ hvert fald været af passiv art, d. v. s., at man har taget disse sange til sig og sunget dem. At tage imod kultur er $i$ sig selv en ænseværdig kulturudfoldelse. Dermed er ikke sagt, at traditionen har været aktiv, altså at denne vise og de andre viser i Jens Madsens og Feilbergs bøger skulle være digtet i Hanved sogn eller på egnen $\mathrm{i}$ det hele taget. De kan være kommet som skillingstryk fra København og Haderslev. Men det er dog muligt! I samme sogn sad der en digterbegavelse som kromand Karsten Thomsen i Frøslev, og heller ikke Bendix Hansen i Frøslev var tabt bag en vogn, så hvorfor skulle der ikke have siddet mindre lys rundt om $i$ de tre herreder?

Under alle omstændigheder er der tilstrækkelig grund til at regne sognet for en dansk kulturprovins endnu i 1910, som det ses. Og sognets danske kulturtradition blev sangbund for et af genforenings- 
tidens skønneste Sønderjyllands-digte, »Hanved «, af Kai Friis Møller, dattersøn af sognepræsten i Hanved i 1864, Immanuel Friis. Det kan nemmest læses i Sprogforeningens Almanak for 1970.

Vor vise viser selv en af de veje, som denne danske kulturstrøm kan have fulgt: soldatertjenesten. Om dennes indflydelse på sydslesvigeres kendskab til det danske rigssprog kan man få en anelse, når man ser, at Lourents Petersen $\mathrm{i}$ "Nørre og Sønder Gøs herred * fortæller om lærer Jens Petersen i Løvensted i Fjolde sogn, at han som ung under garnisonslivet i Nyborg havde haft nogen lejlighed til at lære det danske skriftsprog og det dannede talesprog at kende. Spørgsmålet er da blot: hvor mange sydslesvigere har tjent som soldater i dansktalende egne? Vist nok ikke så få. Slesvigske Infanteriregiment, det nuværende Slesvigske Fodregiment i Haderslev, lå under Englænderkrigen flere år på Falster.

Jens Madsens tale i Lundsgård Vesterskov.

Jens Madsens første fremtræden var en tale ved et folkemøde. Det gik storartet, det vil sige, det var der delte meninger om. Det var på det store danske folkemøde i Angel. Fredag den 20. juli 1860 mødtes 1500 angelboer med 500 tilrejsende fra kongeriget, fra Nordslesvig og Flensborg. Gxsterne kom med dampskibe alle vegne fra og lagde til ved Langballeå og gik derfra op til Lundsgård Vesterskov, der ligger lidt østligt ovenfor Langballeå med en vidunderlig udsigt over Flensborg fjord, Lille Bxlt og Østersøen.

Mødets formål var at knytte bånd mellem danske i Nordslesvig og Mellemslesvig, som man sagde dengang. Også københavnske studenter var med, blandt dem den unge Georg Brandes. Han var så lidt interesseret $\mathrm{i}$ mødets egentlige formål, at han end ikke vidste, hvor mødet blev holdt, og det ved hans udgiver heller ikke. Den skønne ånd, æsteten, overmennesket Georg Brandes var fraværende den dag. Til gengæld var erotikeren af samme navn til stede. Hans attrå gjaldt dels en frøken Schmidth, som åbenbart hørte til det bedre borgerskab i Flensborg, dels en navnløs ung pige. »Under dansen klyngede hun sig ind til mig, jeg blev beruset, trykkede hende ind til mig og dansede bestandig. Mine sanser brusede«, og han ærgrede sig over at se, hvorledes en anden mere formålsfast havde fremgang: "En ækel Flensborger flab bestræbte sig for at forføre en ung køn pige, der stadigt gjorde mindre modstand «. Talerne interesserede ham mindre. 


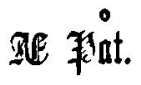

\$a vả jet Báy en ßrât, han vå iả rịk, te be be

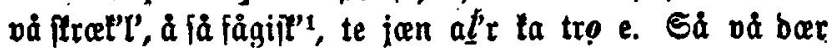

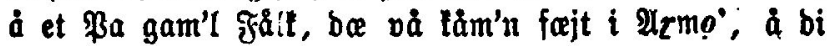

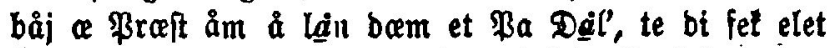
å fåten; fạit pålt' vå bi, å it haj bi Brotrám'r $i$ a Sus. Wian a ßrât lu en' ¥ạn meit. Di båj jå fajt à blöw ve à han $i$, han måit ba jạ ter ${ }^{2}$ \& bam.

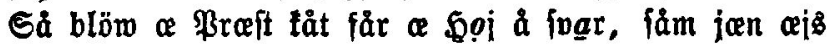

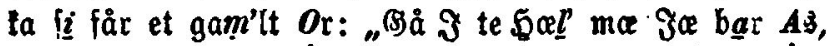

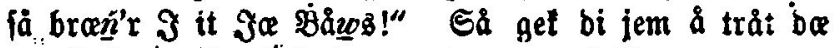
gam'l Ro ụr å vil fael en; man en vå få arm, te en

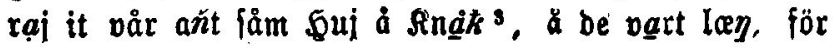

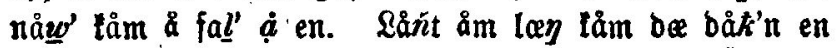
gam'l אạl å båi en ßåt Brọ' fảr en, man bi vil ba tre

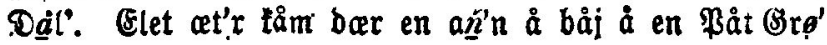
å tefifit en triqu å båj be fam, à ham flảm bi en te $\mathfrak{a}$

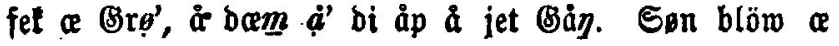

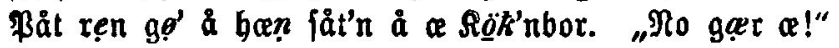
foj $\propto$ ßåt, å bañ get åp te $\mathfrak{a}$ ßrạt's, jawnt fâm bi ftåm.\& mat $\Re$ lăw åp, å law di it haj me' Sal', fult bi å $\propto$ ßåt, å bi hnp's en eñoa fåc å fả åp mat àlt, va

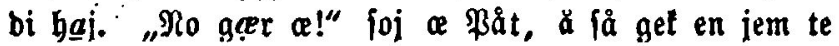
bi arm frålt ma be, à tömt en ay å fảt en han \&

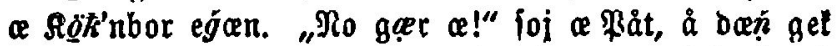
et jet (Bản åp te $\mathfrak{a}$ ßrait. Då fiåm ban joit $\mathfrak{a}$ bå

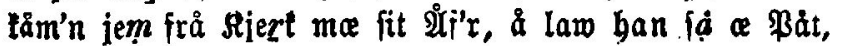

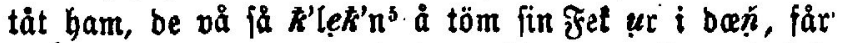

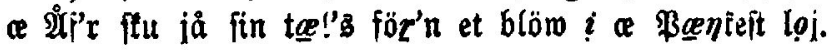

1 gietrig. 2 Gjalpe. 3 snotler. \& toppede. "belejligt. 
\$lan law han baj ge' be, foi a ßåt: „No gael a!"

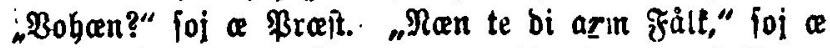
\$åt, å få get en. Di tömt en jå gåm tạ̣ à låt en been a a Sök'nbor eğcen, fåm bi plei' van. "No gaer

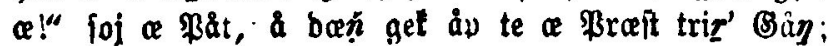

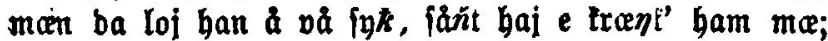

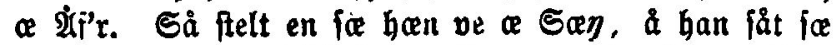
$\dot{a}$ en $i$ et novan' 2(Er'n. "No ge: $a$ !" foj $\propto$ ßåi.

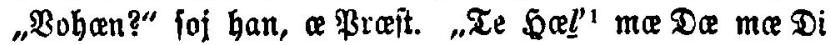

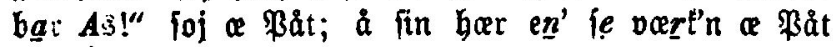
el'r $\dot{a}$ ßreft bat.

\section{Trekler.}

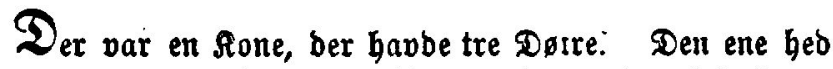
Marie og var henbez Stebbatter, ben anben heb Saren og var hendes egen. $\mathfrak{R}$ var Stebbatteren ben imul: feite, berior tunbe Moberen iffe libe henbe og fittebe henbe en Dag hen til et Bjerg, hoor ber iffe var godt at fomme, for at plutle $\mathfrak{B a r}$. Saa, ba bet blen hen ab Iften, tom Bjergmanden ub til henbe og talbte Gende inb $i$ Bjerget, hoor ban boebe alene med fin Sat. Saa fulde be have noget at fpife, og faa ipurate Bjergmanden Gende, hoab hun belft vilbe, enten fpife fammen med Gam eller meb Satten. Sa hun vilbe jo not fpife meb fatten. "Saa lom og fpiz meb mig," jagbe Bjerg= mauben. Da be flulbe $i$ Seng, fpurgte ban igjen, om hun vilbe fove $i$ hans Seng eller bos Ratten. Ja, bun vilbe not fove hos Autten. "Saa lag Dig $i$ min

1 Selvebe. 2 Brubitgtter. med lydskrift. Naturlig storrelse). 
Ernst Trier var også med: "Nu samledes man om talerstolen, hvorfra al "politik « var bandlyst. En mængde taler blev holdt. $O$, angst og bxven! hvor skulle man være forsigtig. De fleste talere erstattede $\mathrm{da}$ det, der ikke måtte siges, med vrøvl. Kun én rigtig god tale blev holdt af en skolelærer Madsen. Han talte for modersmålet«.

Talerne, og dermed også Jens Madsens, kender vi fra et referat, som ganske givet er så officielt, som det kunne være, af en af dem, der sad i festkomiteen, eller af degn Wethje. Det findes i Flensburger Zeitung den 23. juli 1860. Til sidst hedder det: »Schließlich hielt der Schullehrer Madsen aus Ellund einen nicht bei dem Festcomité angemeldeten, improvisirten Vortrag über die Muttersprache, die dänische Sprache, welche alle Anwesenden nicht allein verstehen, sondern auch sprechen konnten, und brachte ein Hoch auf dieselbe aus«. (Endelig holdt skolelærer Madsen fra Ellund et ikke ved festkomiteen anmeldt, improviseret foredrag om modersmålet, det danske sprog, som alle de tilstedeværende ikke alene kunne forstå, men også tale, og udbragte et leve for det).

Det sure referat skyldes vel mindre frygt for vanskeligheder med myndighederne end ærgrelse over, at sådan et ungt menneske trænger sig på i den ellers fine række af fremtrædende folk.

Festkomiteen bestod af de ansete bønder P. Brodersen fra Stenderup, J. H. Bruhn fra Munkvolstrup, F. N. Böttger fra Hatlund, $H$. Hinrichsen fra Dollerup, og formanden var $M$. Lorenzen fra Lundsgård Vesterskov, på hvis jorder festen vel blev holdt. Det var de samme gode danske mænd, som var styrelse for den danske læseforening i Angel.

Det var naturligvis $M$. Lorenzen, der bød velkommen og udbragte et nifoldigt leve for kongen, hvorefter man sang "Kong Christian«. Dernæst bød degn og lærer i Munkbrarup Claus Peter Wethje nordslesvigerne velkommen, og han var ingen hr. Hvemsomhelst. For det første var han angelbo og født i Grumtoft sogn, hvor ogsa festen holdtes. Dernæst havde han tjent hæren i 17 år og havde hørt til dens stærke og smidige rygrad: underofficerskorpset. Han forlod hæren som overkommandersergent, hvad der ikke var så latterligt som i "Hyrdinden og Skorstensfejeren ", men var en særdeles betroet stilling, og han var da også i 1850 blevet Dannebrogs-mand, en sjælden og fornem udmærkelse. Dernæst talte Laurids Skau, amtsforvalteren, som han korrekt kaldes, men dertil kom, at han var 
medlem af den slesvigske stænderforsamling og leder af den danske gruppe; han var på sit livs højdepunkt og den fremmeste fører blandt danske sønderjyder. Efter ham udbragte den højt ansete og lige så højt elskede flensborgske fysikus - vi ville sige amtslæge dr. Duseberg et leve for $\gg$ Danmark $«$. Det var både da og siden Dusebergs specialitet, hvorefter Laurids Skau atter tog ordet. Georg Brandes noterer ganske kort "Laurids Skau's djærve taler".

Og så er det altså, at den unge 27-årige lærer fra den lille skole $i$ det afsides liggende Ellund, en fattig landsby omgivet af mose og sand $i$ det vidtstrakte Hanved sogn, ganske uopfordret og uden at melde det $\mathrm{i}$ forvejen til den velbestaltede festkomité tager ordet og taler for modersmålet. Men vi kan forstå på Ernst Trier, at talen ikke var så ringe endda, og Trier opsøgte Jens Madsen på mødet og havde en samtale med ham.

Vi véd ikke, hvad Jens Madsen sagde $i$ enkeltheder, men, som vi senere skal se, kan vi næsten få at høre, hvordan han sagde det.

På festpladsen vajede Dannebrog. Der blev skudt med kanoner både først og sidst. Der var telte med mad og drikke og et festmåltid med 400 deltagere og flere taler. Der var karruseller, jonglører og »kropskunstnere«. Der var musik og en danseestrade, hvor Georg Brandes gjorde tilnærmelser til unge piger. De københavnske studenter gav sange til bedste, og om aftenen var der flammende fakler, fortæller Georg Brandes, »mens fyrværkeriet spruttede og knitrede omkring ham. Nogle studenter sad på marken omkring brændende begkranse. En gammel Angel-bonde holdt ilden vedlige, syngende danske sange; ganske henrykt, med tårer i øjnene gik han omkring, trykkede de unge $\mathrm{i}$ hånden og takkede dem, fordi de var kommet. Det var sært højtideligt og smukt «.

Dette minder ikke så lidt om et nutidigt dansk årsmøde i Sydslesvig og er alligevel så forskelligt derfra, at vi måske kunne lære noget af vore forgængere. Der går en mærkelig lige, omend skjult, linje mellem festen ved Lundsgård Vesterskov i 1860 og vore nuværende årsmøder, for taleren dengang, skolelærer Jens Madsen, havde blandt sine skolebørn i Ellund en pige, der hed Gunder Marie Lassen, født i 1847. Hun blev senere, i 1877, moder til redaktør Ernst Christiansen, Flensborg Avis, og vi fejler næppe, når vi tror, at den folkelige ild, som Jens Madsen tændte $i$ hende, blev bragt videre til sønnen, og det var Ernst Christiansen, som startede de 
danske folkemøder på Frøslev Polde i 1920'erne og senere de danske årsmøder i Sydslesvig."

Jens Madsens digt.

Varmen og lyset fra den folkelige ild hos Jens Madsen mærker vi $i$ et digt, som han fik trykt i Nordisk Skole-Tidende i 1862, og af digtet kan vi næsten høre, hvordan han har talt på folkemødet i Lundsgård Vesterskov og i skolestuen i Ellund. ${ }^{3}$ Det gengives med sin egen retskrivning, som var moderne og meget udbredt blandt fremskridtsvenlige lærere i $1850^{\prime}$ erne, og som også Chr. F. Monrad og Jens Jessen var tilhængere af og brugte $i$ deres private brevveksling. En enkel åbenlys trykfejl er rettet. Nordisk Skole-Tidende sparede plads ved at udelade mellemrummene mellem de firelinjede vers. Det var synd, og det bøder vi på her, og vi sxtter numre ved versene.

Til Sender-Jylland.

1. Mit gamle Søndenå, så mørk Du står, din Genius så dybt bedrøvet græder; din stolte Søn i fremmed Trxldom går, og søger ikke mere Hjemmets Glæder.

2. Dog trøst Dig, han vil vende om en Gang og atter satte sig i Moders Stue og synge Dig så kxk og dansk en Sang, at Ungdoms-Glæden i Dit Blik skal lue.

3. Hr. Tønne red sig over Alsø hen, der dåred ham den falske Dværgedarter, dog Runeslaget blev jo løst igen, og frit og frejdigt red Hr. Tønne atter.

4. Din vakre Søn var sig en Ungersvend alt som Hr. Tønne på en vælig Ganger, Han dåret blev, men rider frit igen, når Tysklands Ugle flyr for Hjemmets Sanger.

5. Hr. Vismer drak af Ellefruens Krus, og Moder, Brud og $\mathrm{Hjem}$ randt ham af Minde, dog tro mig, til sit vante gamle Hus skal nok Hr. Vismer atter Vejen finde.

6. Din stolte Søn har drukket dybt som han, den tyske Ellefrue ham bedåred; dog sig mig, kan en $x$ gte nordisk Mand for Alvor glemme den, hans Hjarte kåred? 
7. en fremmed Skønhed kan han smile til, sært, når hun fra hans $H$ jærte kogler Mindet, men hun må kogle, som hun kogle vil, en Gang fra $\varnothing$ jet river han dog Bindet,

8. og aldrig kan en xgte nordisk Mand sin Moder glemme for en fremmed Kvinde; han mindes tit og dybt sin Barndoms Strand, sin Moders Favn han nok igen skal finde.

9. Din Søn, mit kære gamle Søndenå, de lyse Sunde aldrig kan forglemme, når Bindet falder, som han bxrer på, skal han nok vide, hvor han end har hjemme,

10. skal han nok mindes Brudens fagre Bo og Moders kxre Hytte hist ved Stranden, så svinger han sin Hest på gyldne Sko og gi'r den tyske Ellefrue Fanden -

11. så vil $\mathrm{Du}$ glemme al Din Sorg og Ve, $o g$ han vil synge om sin fundne Lykke, så vil hans danske Brud blåøjet le og til sit unge Hjarte glad ham trykke.

Ellund ved Flensborg i Juni 1862.

Jens Madsen.

Digtet er et fuldgyldigt udtryk for den fædrelandsfølelse, der var særegen for 1850-60'erne. Efter formen og dermed litterærhistorisk hører det til tidens talrige bevidst-nutidige folkevise-digte og er afgjort ikke det ringeste af dem. Selv om nutiden har svært ved at tage den mystisk-romantisk-sorgfulde tone, kan også den glædes ved digtet, ikke mindst på grund af den kraftige skæmt i næstsidste vers, der åbner vej for den glade slutning.

Der melder sig straks det spørgsmål: hvor har Jens Madsen sit stof fra? Hertil svarer universitetslektor Karl Clausen:

Der kan ikke være nogen tvivl om, at Jens Madsen hentyder til viserne »Hr. Tønne fra Als« og » Elvehjem«, der begge står $\mathrm{i}$ "Danske Kxmpeviser til Skole-Brug, udvalgte og tillæmpede af Nik. Fred. Sev. Grundtvig«, 1847. Samlingen var godt på vej til at blive højskole-, seminarie- og skolebog. 2. oplag kom i 1875, en melodisamling ved Morten Eskesen i 1869. 
"Hr. Tønne« findes i Abrahamson, Nyerup og Rahbeks »Udvalgte danske Viser ", 1812-14, men "Elvehjem« ikke. "Ælvehjem« er trykt første gang hos Grundtvig 1847 og mærket med *, sandsynligvis efter Grundtvigs kvarthåndskrift nr. 119, men »tillæmpet* af den gamle. Det ses af Svend Grundtvigs "Danmarks gamle Folkeviser « nr. $45 \mathrm{i}$ bd. 2, 1854-56, hvor visen hedder »Hr. Bøsmer i Elvehjem«. Håndskriftets "Bøsmer« er hos N. F. S. Grundtvig blevet til *Vismer«, vel på grund af en læsefejl.

Jens Madsen stod jo i venskabelig forbindelse med Svend Grundtvig som meddeler af viser og andre folkeminder, og han kan jo godt have kendt »Danmarks gamle Folkeviser« bd. 2. Men til folkelig brug er han tyet til "Danske Kæmpeviser « 1847, hvad også navneformen "Vismer « viser.

Selve det at udlægge en vise $i$ lys af den aktuelle folkelig-nationale situation har han vel lært på seminariet i Jelling eller (og?) læst sig til hos Grundtvig, f. eks. Grundtvigs foredrag i Danske Samfund den 23. april 1839, som er trykt i Fr. Barfods "Brage og Idun « 1839. Det handlede netop om »Hr. Tønne«.

Så vidt Karl Clausen.

Skolesproget i Ellund var dansk, og dette holdt Jens Madsen på, da den preussisk-østrigske magt ændrede alle forhold. Den 2. maj 1864 svarede Jens Madsen på et spørgsmål fra Hanved pastorat: "Jeg er på ingen måde villig til hverken at foretage nogen prøve med børnene $i$ det tyske sprog eller for eftertiden $i$ selve skolen at undervise i noget andet sprog end det hidtil i følge allerhøjeste patent befalede«. Følgelig blev han afskediget, men fik samme år et embede som lærer ved Kobenhavns kommuneskoler. ${ }^{8}$ Han glemte ikke sit gamle sogn, Hanved. 8. august 1892 brændte Harreslev by, og 21 familier blev husvilde. Jens Madsen, nu viceinspektør i København, sendte 5 mark til Flensborg Avis' indsamling til de brandlidte. Det var ikke noget lille beløb. Pastor Carstens ved Helligåndskirken gav 10 mark, og næppe har nogen embedsmand givet mere."

1870 udkom så hans »Folkeminder fra Hanved Sogn ved Flensborg ", men han var ikke færdig med folkeminderne endnu. Der ligger adskillige optegnelser af ham i Dansk Folkemindesamling. De er til dels udnyttet af Evald Tang Kristensen $\mathrm{i}$ dennes "Danske Sagn«, 1892-1901, bd. 1-7, og »Almueliv«, 1891-1902, bd. 1-6. 
Jens Madsens anden bog.

Jens Madsen må have følt trang til at udnytte sine folkemindekundskaber på en praktisk pxdagogisk måde, for han udgav endnu en bog, hvis titelblad vi gengiver fuldtud, da bogen ikke er optaget i "Dansk Bogfortegnelse :

Sanglege fra den Köbenhavnske Börneverden 22 Lege med Melodier og forklarende Texter ved Jens Madsen og Viggo Sanne Larere ved Köbenhavns offentlige Skolevesen Med 12 Skizzer af P. Klostrup. Köbenhavn Wilbelm Hansens Forlag og Eiendom. Christiania C. Warmuth. Stockbolm S. Levy.

De manglende punktummer og de sære ö'er skyldes, at omslaget, som samtidig skal gøre det ud for titelblad, er litograferet og komponeret af den nævnte tekst og en smuk helsides tegning af fugle og små nøgne børn i et træ og på en stejlende gedebuk. Det manglende årstal er en meget almindeligt forekommende unode på nodetryksager, hvad årsagen ellers kan være.

Bogen er tilegnet sanginspektør, professor A. P. Berggreen, der døde 1880, og bogen er altså før dette år. Den indeholder tekst og forklaring til en række almindelige sanglege. Teksten har sin særlige værdi ved at indeholde væsentlige afvigelser $i$ forhold til, hvad der nu er gængs $i$ disse omtrent glemte sanglege, og disse afvigelser er sikkert det oprindelige. Munken går $\mathrm{i}$ enge, også i denne bog, men ikke med en skønjomfru. Her er det en nonne, og dette viser, at sangen går helt tilbage til middelalderen, og at den ikke oprindelig var så uskyldig endda og slet ikke nogen børnesang. Hertil kommer 12 litograferede blade, hvor Klæstrup viser optrin af 24 sanglege og slutter bogen med et billede af en pige, der spiller klaver, og en dreng, der synger til. Når omslaget tælles med, består bogen af 48 sider i formatet $16^{1 / 2} \times 25^{1 / 2} \mathrm{~cm}$, hvortil skal lægges de millimeter, som bogbinderen har skåret fra. Bogen er sjxlden.

Den er også på en mærkelig måde en arv fra den gamle dansknorske helstat. Jens Madsens medarbejder, Viggo Sanne (1840-96), sørgede for musikken til bogen, for der er noder ved alle sangene. Sanne blev siden sanginspektør og kom til at betyde meget for skolesangen i Danmark. Han er udtryk for den norske del af helstaten, for han er født i Kristiania i 1840, hvor hans fader var gæstgiver. Faderen var dog ikke mere norsk, end at han var født $i$ København og i 1842 drog til København, da han ikke kunne leve af at være gæstgiver for nordmænd. 
Den tredje i bundtet, Peter Klæstrup, var ærkekøbenhavner, født i Trinitatis sogn, død i Vor Frue sogn og begravet på Assistens. Mere end nogen anden har han fastholdt det gamle København $i$ sine akvareller, tegninger og træesnit, men efter mit skøn er illustrationerne her $\mathrm{i}$ bogen litografier. Han levede 1820-82.

Jens Madsen var vestjyde, barnefødt i Ure i Lejrskov sogn. Han blev viceinspektør i 1885, blev pensioneret i 1906 og døde i $1907 . .^{10}$ Hans rigeste arbejdsår er vel de seks i Sønderjylland, men han nåede $\mathrm{da}$ at samle sanglegene op fra storbyens brosten og bringe dem ind i denne bog. Nutiden hxlder mere eller mindre bevidst til den opfattelse, at menneskelige og levende, børneglade lærere først er kommet ind i skolen i vore dage, men det er da heldigvis galt. Børnekære og -kyndige lærere som Jens Madsen har der altid været.

\section{NOTER}

1. Nis Jensen var fader til statskonsulent Johannes Jensen.

2. (Maar?) er Nis Jensen Branderups tilføjelse, som sikkert er rigtig.

3. G. Japsen: Det dansksprogede skolevæsen i Sønderjylland indtil 1814. 1968. Side $230 \mathrm{f}$.

4. Karl Clausen: Es können passieren ... Es sind vorzuenthalten ... Zensur deutscher und dänischer Lieder in Tondern 1830-1847. I: Jahrbuch für Volksliedforschung 1970. Larer Lasthein fortaller i sine minder om markedsture fra Store Vi til Bredsted. Se Sydslesvigsk Kirkekalender 1950 eller L. S. Ravn: Lærerne under sprogreskripterne 1851-1864. 1971. (I trykken).

5. Broder Ketelsens danske optegnelser findes i Studieafdelingen i Dansk Centralbibliotek for Sydslesvig, Flensborg.

6. Flensburger Zeitung 23. juli 1860.

Georg Brandes: Dagbogsblade fra en Rejse i Slesvig 19. Juli-26. Juli 1860. 1957. Side $33 \mathrm{ff}$.

Georg Brandes: Levned. 1905. Bd. 1, side 100.

Povl Hansen: Højskoleforstander Ernst Trier. 1929. Bd. 2, side 17.

Troels Fink: Da Ernst Christiansen blev oopdaget«. SJy Årb 1970, side 120. Flensborg Avis. 1869 1. oktober 1969. Redigeret af Poul Kürstein. 1969. Side $199 \mathrm{f}$.

7. Nordisk Skole-Tidende. Lordag den 30 Avgust 1862. No. 10 (1862, bd. 4, side 154-55).

8. L. S. Ravn: Larerne under sprogreskripterne 1851-1864. 1971. (I trykken).

9. Flensborg Avis. 28. august 1892.

10. Trods Jens Madsens ret vigtige virke både som skolemand og forsker findes der intet billede af ham $\mathrm{i}$ vore samlinger, hverken i Det kongelige Bibliotek, Pædagogisk Studiesamling, Dansk Folkemindesamling eller i Historiske Samlinger for Sønderjylland. Ej heller i Københavns skoledirektion. Studieafdelingen ved Dansk Centralbibliotek for Sydslesvig, Flensborg, vil meget gerne låne et billede. 